\title{
Tomato linalool synthase is induced in trichomes by jasmonic acid
}

\author{
Chris C. N. van Schie • Michel A. Haring • \\ Robert C. Schuurink
}

Received: 13 December 2006/Accepted: 8 February 2007/Published online: 12 April 2007

(C) Springer Science+Business Media B.V. 2007

\begin{abstract}
Tomato (Lycopersicon esculentum) plants emit a blend of volatile organic compounds, which mainly consists of terpenes. Upon herbivory or wounding, the emission of several terpenes increases. We have identified and characterized the first two tomato monoterpene synthases, LeMTS1 and LeMTS2. Although these proteins were highly homologous, recombinant LeMTS1 protein produced $(R)$-linalool from geranyl diphosphate (GPP) and $(E)$-nerolidol from farnesyl diphosphate (FPP), while recombinant LeMTS2 produced $\beta$-phellandrene, $\beta$-myrcene, and sabinene from GPP. In addition, these genes were expressed in different tissues: LeMTS1 was expressed in flowers, young leaves, stems, and petioles, while LeMTS2 was strongest expressed in stems and roots. LeMTS1 expression in leaves was induced by spider mite-infestation, wounding and jasmonic acid (JA)-treatment, while LeMTS2 did not respond to these stimuli. The expression of LeMTS1 in stems and petioles was predominantly detected in trichomes and could be induced by JA. Because JA treatment strongly induced emission of linalool and overexpression of LeMTS1 in tomato resulted in increased production of linalool, we propose that LeMTS1 is a genuine linalool synthase. Our results underline the
\end{abstract}

C. C. N. van Schie · M. A. Haring · R. C. Schuurink ( $ه)$ Swammerdam Institute for Life Sciences, Department of Plant Physiology, University of Amsterdam, 1098 SM, Amsterdam, The Netherlands

e-mail: rschuuri@science.uva.nl

Present Address:

C. C. N. van Schie

University of California, San Diego, 9500 Gilman drive, La Jolla, CA 92093-0380, USA

e-mail: cvanschie@ucsd.edu

M. A. Haring

e-mail: haring@science.uva.nl importance of trichomes in JA-induced terpene emission in tomato.

Keywords Tomato - Jasmonic acid - Trichomes . Linalool $\cdot$ Terpenes $\cdot$ Defence

\section{Introduction}

Plants produce a wide variety of terpenoids that have primary functions as hormones (gibberellins, abscisic acid, brassinolide), sterols, pigments (carotenoids, phytol), and as parts of electron carrier moieties (ubiquinone, plastoquinone) (McGarvey and Croteau 1995). Most terpenoids, however, are secondary metabolites: over 20,000 different terpenoid structures from plants have been described (Sacchettini and Poulter 1997). Some terpenoids function in the direct defence strategy of plants as phytoalexins, which accumulate upon pathogen infection. Sesquiterpene phytoalexins (e.g., capsidiol) are characteristic for the Solanaceae (Chappell and Nable 1987; Egea et al. 1996).

Volatile monoterpenes and sesquiterpenes can function in the interaction of plants with other organisms. They are present in floral scents that attract pollinators (Knudsen et al. 1993; Langenheim 1994) and are emitted by many plant species in response to herbivory by insects or spider mites. Induced terpene emission can attract predators or parasitoids of the herbivores, a mechanism commonly referred to as the indirect defense strategy of plants. This has been studied in, for instance, Arabidopsis (Arabidopsis thaliana) (Van Poecke et al. 2001), lima bean (Phaseolus lunatus) (Dicke 1994; Takabayashi and Dicke 1996), tobacco (Nicotiana tabacum; N. attenuata), maize (Zea mays), and cotton (Gossypium hirsutum) (De Moraes et al. 
1998; Pare and Tumlinson 1999), and tomato (Kant et al. 2004; Takabayashi et al. 2000).

These volatile terpenes are produced by sesqui- and monoterpene synthases of which several are induced by herbivory. For instance, nerolidol synthase activity is induced in lima bean, cucumber (Cucumis sativus), and maize (Bouwmeester et al. 1999; Degenhardt and Gershenzon 2000), whereas transcript levels of various other sesquiterpene synthases increase in, amongst others, maize (Shen et al. 2000), cucumber (Mercke et al. 2004), and wormwood (Artemisia annua) (Cai et al. 2002). In Arabidopsis, caterpillars (Pieris rapae) induce the myrcene/ocimene synthase AtTPS10 and the $\beta$-ocimene synthase AtTPSO3, which coincides with increased myrcene emission (Van Poecke et al. 2001). Moreover, a $\beta$-ocimene synthase ( $L j E \beta O S)$ has been identified from Lotus (Lotus japonicus), which is induced by spider mitefeeding, resulting in increased emission of $\beta$-ocimene (Arimura et al. 2004b). However, artificial wounding or jasmonic acid (JA) treatment are often also sufficient to induce terpene synthases. The wound- and JA-induced synthesis of terpenes by coniferous plants is well described (Martin et al. 2002; Miller et al. 2005; Steele et al. 1995), and these treatments also mimic herbivore-induced responses in several angiosperms (Arimura et al. 2004a; Gomez et al. 2005; Schnee et al. 2002; Shen et al. 2000).

Here we describe the identification and characterization of the first two monoterpene synthases from a solanaceous species (tomato), LeMTS1 and LeMTS2. We provide evidence that these genes are differentially regulated and more importantly, that expression of linalool synthase LeMTS1 is restricted to trichomes and induced by JA.

\section{Results}

Identification of tomato terpene synthases 1 and 2 (LeMTS1 and LeMTS2)

In order to identify tomato monoterpene synthases that are induced upon spider mite herbivory, we first queried tomato EST databases (www.tigr.org and www.ncbi.nlm.nih.gov/BLAST/) with known monoterpene synthase sequences from other plant species. Retrieved tomato EST sequences were used to design a primer specific for monoterpene synthases (Fig. 1). We then used cDNA derived from spider mite-infested plants, to amplify a single $850 \mathrm{bp}$ fragment with this primer and an oligo $\mathrm{dT}(18)$ primer. This fragment was subsequently used as a probe to screen available tomato cDNA libraries. Two different full-length cDNAs were identified; LeMTS1 (AY840091) was isolated from tomato leaves (sequence identical to the probe) and LeMTS2 (AY840092) from tomato roots and stems. The LeMTS1 and LeMTS2 open reading frames encode proteins of 609 and 590 amino acids (Fig. 1), which have predicted masses of 70.8 and 68.6 $\mathrm{kDa}$, respectively, and are $71 \%$ identical. LeMTS1 and LeMTS2 contain amino acid motifs conserved in angiosperm (mono)terpene synthases. These are, based on LeMTS1 amino acid positions: $\mathrm{R}(45) \mathrm{R}(46) \mathrm{W}(55)$, required for the initial diphosphate migration (Williams et al. 1998); $\mathrm{D}(362) \mathrm{D}(363) \mathrm{D}(366)$, required for binding of $\mathrm{a} \mathrm{Mg}^{2+}$ or $\mathrm{Mn}^{2+}$ ion, which is used as cofactor (Cane et al. 1996; Starks et al. 1997); $\mathrm{D}(505) \mathrm{T}(509) \mathrm{E}(513)$, required for binding of a second $\mathrm{Mg}^{2+}$ or $\mathrm{Mn}^{2+}$ cofactor; and $\mathrm{D}(586)$ in the active site cleft (Schwab et al. 2001; Whittington et al. 2002). LeMTS1 and LeMTS2 contain both putative (predicted with TargetP; Emanuelsson et al. 2000) plastid targeting signal peptides, which should be processed in the region upstream of the conserved $\mathrm{R}(45) \mathrm{R}(46)$ arginine pair.

Remarkably, LeMTS1 contains an extra sequence stretch of 22 amino acids starting at N170 (Fig. 1). This sequence is not found in any other terpene synthase, nor does it have homology to any protein in the NCBI database (www.ncbi.nlm.nih.gov/BLAST/). Its presence can also not be explained by alternative splicing since the flanks do not contain canonical splice sites. This extra internal element is not an artefact of the isolated cDNA since it was present in four independent cDNAs isolated from different organs (data not shown).

LeMTS1 and LeMTS2 belong to the TPSb subfamily of terpene synthases

LeMTS1 and LeMTS2 are more similar to typical monoterpene synthases from, e.g., mint and citrus than to a typical tomato sesquiterpene synthase (Fig. 1). Based on protein sequence relatedness, LeMTS1 and LeMTS2 can be classified in the TPSb subfamily (Fig. 2), a distinct group of angiosperm monoterpene synthases, according to the original classification proposed by Bohlmann et al. (1997). So, unlike the snapdragon (Antirrhinum majus) monoterpene synthases from subfamily TPSg (Dudareva et al. 2003), including an Arabidopsis and a strawberry terpene synthase, the monoterpene synthases from the solanaceous family do not seem to form a new subfamily.

Terpene synthase activity of recombinant LeMTS1 and LeMTS2

Recombinant LeMTS1 and LeMTS2 proteins were produced in Escherichia coli in order to characterize their enzymatic activities. The plastid targeting peptide was deleted up to one amino acid upstream of the $\mathrm{RRX}_{8} \mathrm{~W}$ motif (Fig. 1) to produce a His-tagged 'pseudo-mature' form of the proteins, since it has been reported that this can 

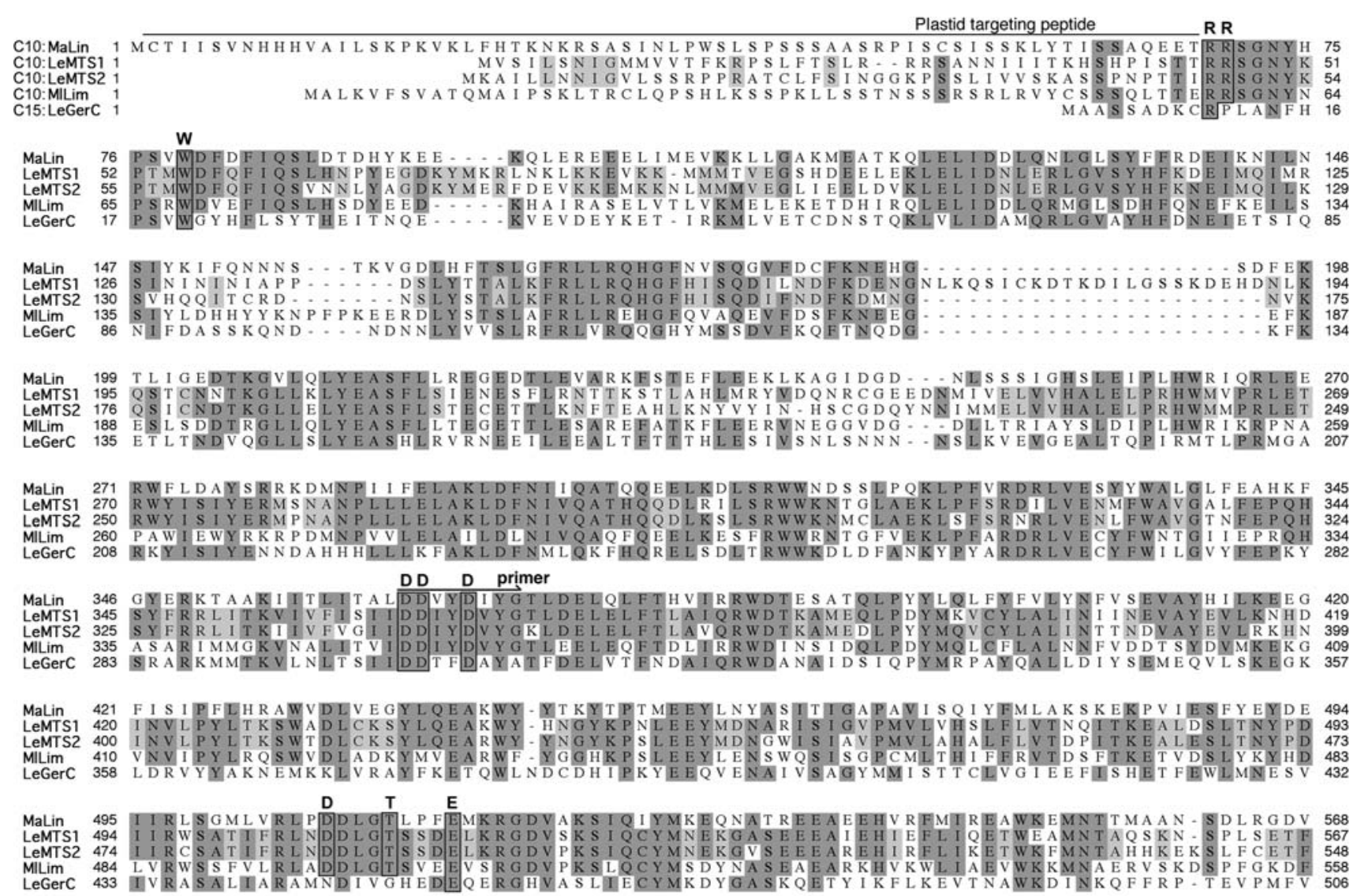

\section{D}

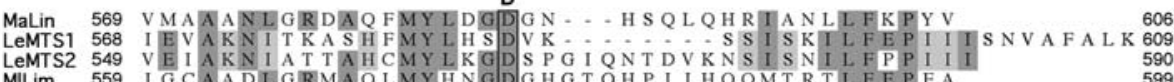

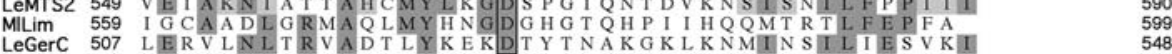

Fig. 1 Alignment of deduced amino acid sequences of LeMTS1 and LeMTS2 with three terpene synthases. A ClustalW alignment is shown of Mentha aquatica linalool synthase, a monoterpene synthase (C10), MaLin (AAL99381); Lycopersicon esculentum monoterpene synthase 1, LeMTS1 (AY840091); L. esculentum monoterpene synthase 2, LeMTS2 (AY840092); Mentha longifolia limonene synthase, MlLim (AAD50304), and L. esculentum germacrene C synthase, a typical sesquiterpene synthase (C15), LeGerC (AAC39432). Amino acids are shaded dark if identical in at least

improve protein expression without affecting activity and product specificity of the enzymes (Bohlmann et al. 1999; Williams et al. 1998). The soluble protein fractions were assayed for terpene synthase activity and products were analyzed on a GC coupled to a Time Of Flight-MS. Using the monoterpene precursor geranyl diphosphate (GPP) as substrate, LeMTS1 generated only linalool whereas LeMTS2 generated several monoterpene products: $\beta$-phellandrene, $\beta$-myrcene, and sabinene (Fig. 3a). Mass spectra and relative retention indices (Adams 2001) or authentic standards confirmed the identification of terpene reaction products. Extracts of E. coli cells expressing the empty vector control generated minor amounts of linalool (Fig. 3a) and occasionally geraniol. Thermally induced autoconversion or solvolysis of GPP to linalool has been three of the five sequences and light if identical in LeMTS1 and LeMTS2 only. Conserved amino acid motifs typical for terpene synthases are boxed: $\mathrm{RRx}_{8} \mathrm{~W}$ (Williams et al. 1998), DDxxD (Cane et al. 1996; Starks et al. 1997), $\mathrm{Dx}_{3} \mathrm{Tx}_{3} \mathrm{E}$, and D (Schwab et al. 2001; Whittington et al. 2002). The presence of putative N-terminal plastid targeting peptides in the four monoterpene synthases and the primer used for amplifying the initial LeMTS fragment from cDNA of spider mite-infested leaves are indicated

observed before (Crowell et al. 2002; Jia et al. 1999), as well as conversion to geraniol by aspecific hydrolase or phosphatase activity in protein extracts (Crowell et al. 2002). However, LeMTS1 product levels are several hundred-fold higher than the background levels of the control (Fig. 3a).

Enantiomer separation on an enantiomer-selective column showed that LeMTS1 produced only $(R)$-linalool (data not shown). LeMTS1 was also able to utilize the sesquiterpene precursor farnesyl diphosphate (FPP) as substrate to produce (E)-nerolidol (Fig. 3b), whereas LeMTS2 had no detectable sesquiterpene synthase activity. Both enzymes were unable to form terpene products from the diterpene precursor geranylgeranyl diphosphate. 


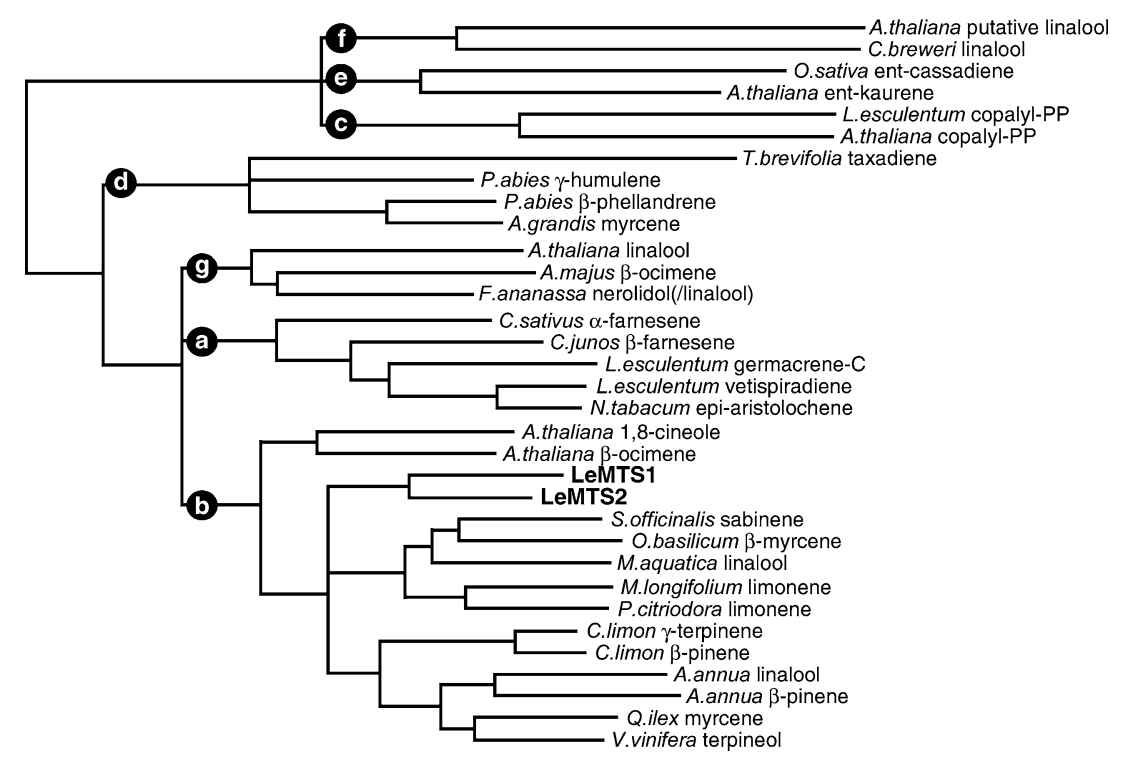

Fig. 2 LeMTS1 and LeMTS2 belong to the TPSb subfamily of terpene synthases. The TPS family is divided into subfamilies according to the nomenclature of Bohlmann et al. (1997). TPSa: angiosperm sesquiterpene synthases, TPSb: angiosperm monoterpene synthases, TPSc: angiosperm diterpene synthases, TPSd: gymnosperm mono-sesqui- and diterpene synthases, TPSe: a second group of angiosperm diterpene synthases, TPSf: a distinct group of (putative) linalool synthases mainly from Clarkia (Dudareva et al. 1996) and TPSg: a recently identified group of monoterpene synthases mainly from Antirrhinum (Dudareva et al. 2003). A limited amount of representative terpene synthases is shown. The bootstrapped phylo- genetic tree was constructed using PAUP and TreeView software. A representative tree of 100 replicates is shown. Genbank protein accessions of terpene synthases shown are, top to bottom: TPSf: AAL24105, AAC49395; TPSe: BAC56714, AAC39443; TPSc: BAA84918, NP192187; TPSd: AAK83566, AAK39129, AAK39127, AAB71084; TPSg: NP176361, AAO42614, CAD57081; TPSa: AAU05951, AAK54279, AAC39432, AAG09949, Q40577; TPSb: NP189212, NP567511, AY840091, AY840092, AAC26018, AAV63791, AAL99381, AAD50304, AAG31435, AAM53943, AAM53945, AAF13356, AAK58723, CAC41012, AAS79351
Fig. 3 Enzymatic activity of recombinant LeMTS1 and LeMTS2 proteins. (A) GC/MS chromatograms of the LeMTS1 and LeMTS2 monoterpene products and the empty vector control with GPP as substrate. (B) GC/MS chromatogram of the LeMTS1 sesquiterpene product and the empty vector control with FPP as substrate. The chromatograms show detector responses for the terpene-specific ion mass 93 . Products were identified as linalool (1), sabinene (2), $\beta$ myrcene (3), $\beta$-phellandrene (4), and (E)-nerolidol (5). Representative chromatograms are shown from assays of at least two independent experiments
(A)

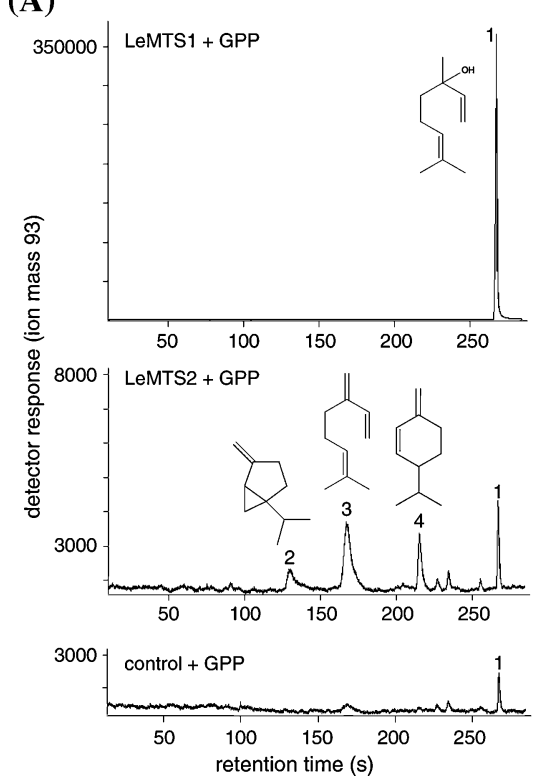

(B)

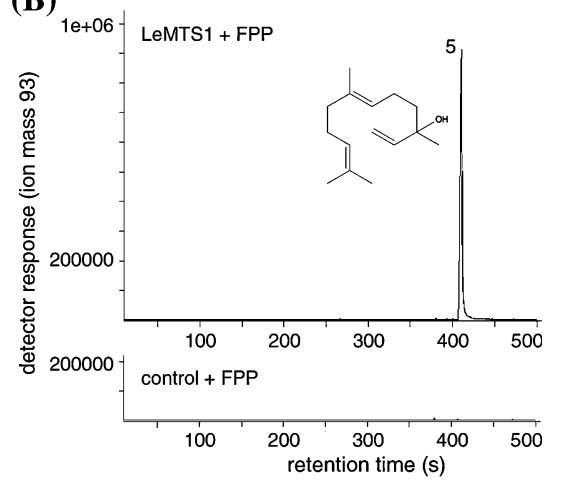

LeMTS1 and LeMTS2 are differentially expressed in various plant organs

We investigated the organ specificity of LeMTS1 and LeMTS2 expression in a mature (13 weeks old) tomato plant (Fig. 4a). Transcripts of LeMTS1 were detected in young fruit, flower buds, petals, sepals, stems, petioles, and in young leaves. The expression pattern of LeMTS2 was very different: no transcripts were detected in petals, sepals, and leaves. However, LeMTS2 was expressed in roots. 

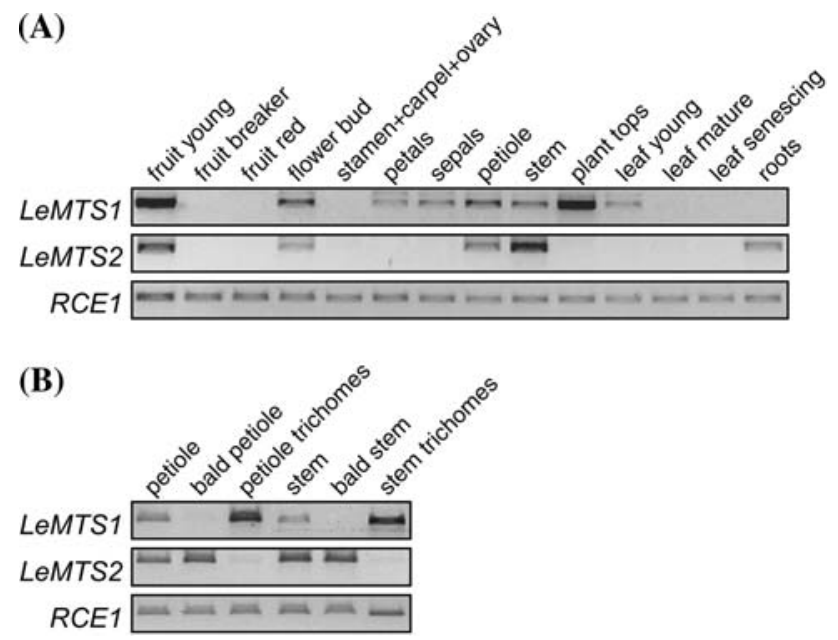

Fig. 4 Spatial expression patterns of LeMTS1 and LeMTS2 in tomato. (A) Expression of LeMTS1 and LeMTS2 in different organs of an adult tomato plant. (B) Expression in trichomes or complementary tissue of petioles and stems. Expression was analyzed by RT-PCR. The data from one of two independent tissue sets that gave similar results is shown. RUB1 conjugating enzyme (RCE1, www.tigr.org: TC153679) was used as constitutive control. Ethidium bromidestained agarose gels are shown

For plants that contain glandular trichomes, monoterpene production is considered to be localized exclusively in these organs (Gershenzon et al. 1992; Iijima et al. 2004; Kutchan 2005; Turner et al. 1999; Turner and Croteau 2004). Tomato plants possess several types of trichomes including glandular trichomes that are present in high density on leaves, petioles, and stems and that contain terpenes (Maluf et al. 2001; Snyder and Carter 1985). Therefore, we investigated the location of LeMTS1 and LeMTS2 expression in trichomes of petioles and stems. This showed that LeMTS1 is expressed in trichomes, whereas LeMTS2 is expressed in the complementary tissue (Fig. 4b).

LeMTS1 but not LeMTS2 is induced by spider mite feeding, artificial wounding, and jasmonic acid

To study whether LeMTS1 and LeMTS2 were induced upon spider mite feeding, changes in transcript levels of intact plants were analyzed by RT-PCR since LeMTS geneexpression was too low to determine by RNA gel-blot analysis. Expression of LeMTS1 was indeed induced in leaves by spider mite-feeding, but LeMTS2, which expression was very low in leaves, was not (Fig. 5a). Spider mites damage plant tissue and induce JA- and SAresponsive genes such as a wound-induced proteinase inhibitor (WIPI-II) and a pathogenesis related protein (PRP6), respectively (Kant et al. 2004). Therefore, we investigated the effects of artificial wounding and exogenous application of JA and SA (Fig. 5a). Both artificial wounding and JA induced LeMTS1. In contrast, LeMTS2
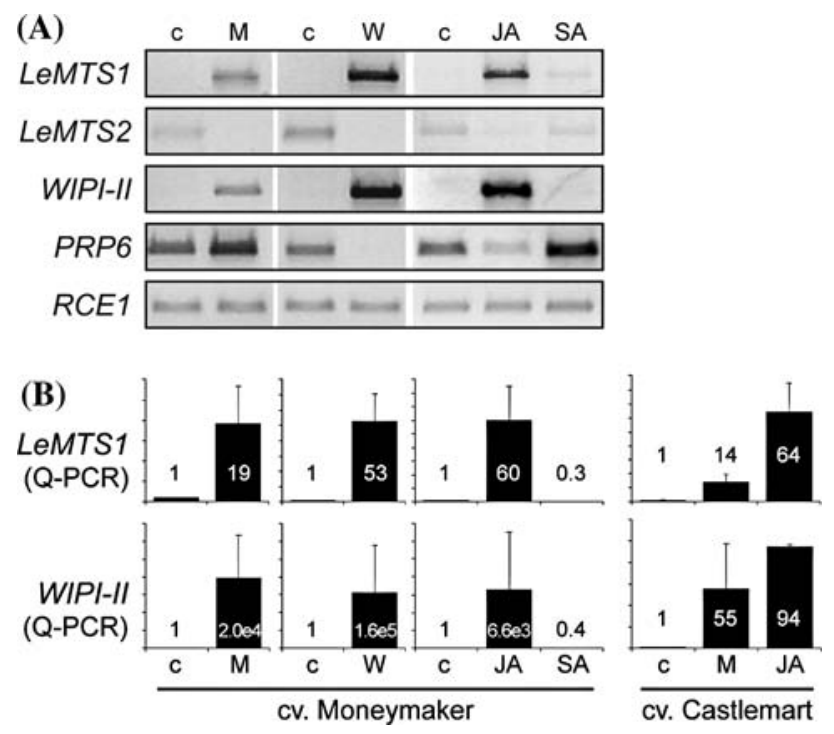

Fig. 5 Induction of LeMTS1 in tomato leaves in response to spider mites, wounding, and jasmonic acid (JA). (A) Gene expression analysis by semi-quantitative RT-PCR of LeMTS1 and LeMTS2 after various treatments, compared to the well known JA- and SA-marker genes WIPI-II (Graham et al. 1985) and PRP6 (van Kan et al. 1992), respectively. Treatments: JA, SA, and artificial wounding (W) after $24 \mathrm{~h}$ and spider mite-infestation (M) after $48 \mathrm{~h}$. A representative result from three independent experiments is shown. RUB1 conjugating enzyme (RCE1) was used as constitutive control. Ethidium bromide-stained agarose gels are shown. (B) Validation of LeMTS1 and WIPI-II induction by real-time Q-RT-PCR. Two different tomato cultivars were used to verify induction by mites and JA. Values represent expression levels relative to controls, calculated after correction for expression of the control gene RCE1 (TC153679, www.tigr.org). Average values and standard errors are shown from three to five independent replicates

was not induced by these treatments (Fig. 5a). SA-treatment induced the SA-marker PRP6 but neither LeMTS1 nor LeMTS2 was increased. Induction of LeMTS1 and WIPI-II was validated by real-time Q-RT-PCR. This showed consistent and clear induction of both genes by JA, artificial wounding and spider mites, although there was large variation in the level of induction between independent experiments (Fig. 5b). We routinely used the tomato cultivar Moneymaker for our experiments. However, in our earlier work (Ament et al. 2004; Kant et al. 2004) the cultivar Castlemart (CM) was used because it has the same genetic background as the defenseless 1 (def-1) mutant (Howe et al. 1996). Here, we show that spider mite- and JA-induced LeMTS1 expression occurred both in CM and Moneymaker (Fig. 5b).

To investigate whether spider mite-induced expression of LeMTS1 was dependent on JA or SA we made use of the def- 1 mutant, which is impaired in induced JA-accumulation (Howe et al. 1996) and the SA-deficient, transgenic $N a h G$ tomato line (Brading et al. 2000). In plants with the def-1 mutation, LeMTS1 was not induced by spider mites, 

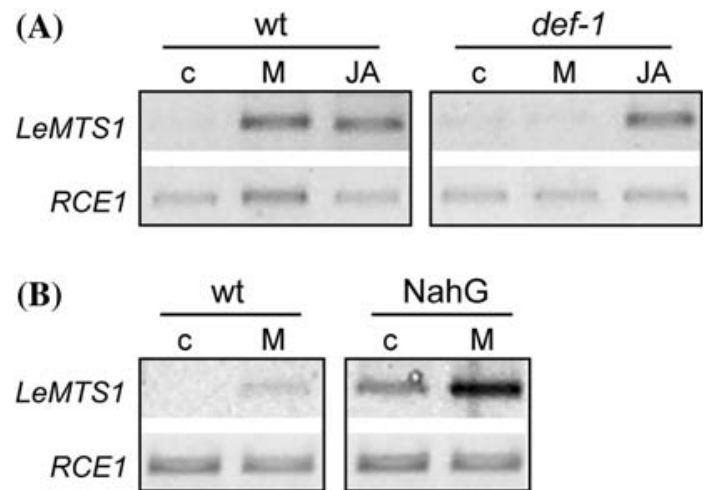

Fig. 6 Spider mite-induced LeMTS1 expression is dependent on jasmonic acid (JA). (A) Expression of LeMTS1 in wild type (wt) or JA deficient $d e f-1$ mutant plants infested with spider mites (M) or treated with JA for 2 days. (B) LeMTS1 expression in wild type and SA deficient $N a h G$ plants in response to 2 days of spider mite-feeding. Gene expression was analyzed by RT-PCR, a representative result from one out of two independent experiments is shown. RUB1 conjugating enzyme (RCEl) was used as constitutive control. Ethidium bromide-stained agarose gels are shown

whereas the expression could be induced by exogenous JA (Fig. 6a). In contrast, the NahG plants showed higher and clearly induced LeMTS1 expression (Fig. 6b). This shows that induction of LeMTS1 expression is dependent on JA but not on SA.

JA induces expression of LeMTS1 in trichomes

Since basal LeMTS1 expression in stems and petioles seemed to be restricted to trichomes (Fig. 4b), we addressed the question whether JA would induce expression of LeMTS1 solely in trichomes or also in other tissues. Indeed, JA-induced LeMTS1 expression was strongest in trichomes (Fig. 7). Interestingly, WIPI-II expression showed the opposite pattern. WIPI-II expression is very low in trichomes and basal as well as strongly induced WIPI-II expression occurred mainly in the complementary stem tissues.

Linalool accumulates in glandular trichomes and linalool emission is induced by wounding, jasmonic acid, and by ectopic LeMTS1 overexpression

Figure $4 \mathrm{~b}$ showed that, in petioles and stems, LeMTS1 was expressed specifically in the trichomes. Extraction of terpenes from the same tissues of that experiment demonstrated that linalool was produced predominantly in trichomes (Fig. 8). (E)-nerolidol and $\beta$-phellandrene also accumulated in trichomes. Conversely, the volatile benzenoid methyl-salicylate was not produced in trichomes and was also clearly detected in roots, in contrast to most terpenes.

Because LeMTS1 was induced by spider mite-infestation, wounding and JA, we investigated whether the emission of its in vitro products was induced concomitantly. Analysis of volatile production during 2 days of wounding or JA-treatment, conditions that induce LeMTS1 expression (Fig. 5), revealed that plants emitted more linalool after both treatments (Fig. 9a), while nerolidol emission was not induced.

Next, we tried to overexpress the full length LeMTS1 cDNA (including the putative targeting peptide) in tomato plants, under control of the CaMV 35S promoter. Four transformation experiments yielded only two transformants of which one overexpressed LeMTS1. Compared to empty vector-transformed plants, LeMTS1 overexpressing plants emitted several hundred-fold more linalool into the plants headspace (Fig. 9b), while emis-
Fig. 7 LeMTS1 is induced in trichomes by JA. Expression analysis of LeMTS1 and WIPI-II by real-time Q-RT-PCR. Intact plants were treated with JA, and subsequently trichomes were separated from remaining tissues of stems. The results from four independent experiments are shown as mean values and standard errors. Expression levels are indicated as expression relative to the control gene RCE1
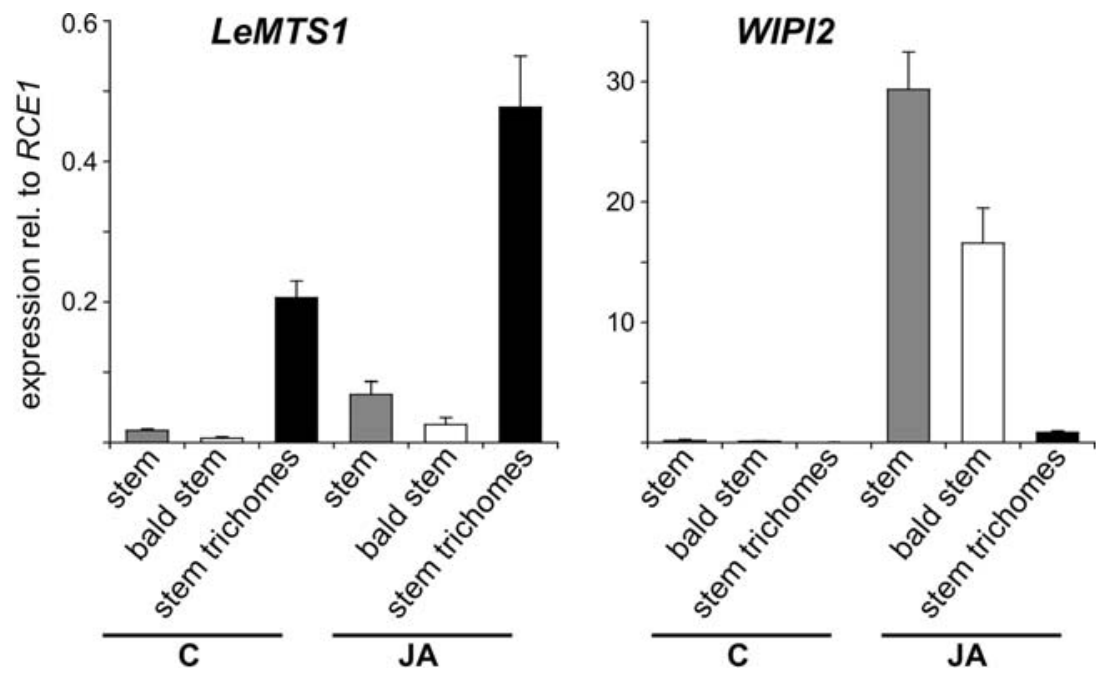


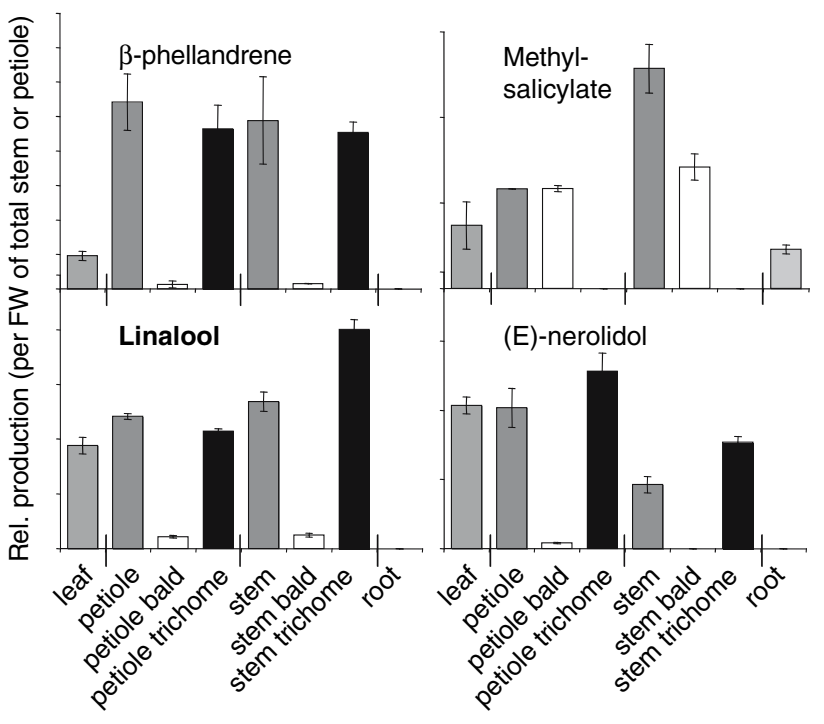

Fig. 8 Linalool accumulation in trichomes. Relative levels of linalool, a selection of other terpenes and methyl salicylate in extracts of petioles and stems before and after removal of trichomes compared to total leaf and root extracts. Equal amounts of the different tissues were used (freshweight, $0.5 \mathrm{~g}$ ), and trichome material was corrected for freshweight of the original petiole or stem. Averages of two measurements and $\mathrm{min} / \mathrm{max}$ are shown

sion of other terpenes, including nerolidol, did not differ significantly from control plants. This suggests that LeMTS1 functions in planta as a true linalool synthase.

\section{Discussion}

Monoterpenes are abundantly emitted by tomato plants. For instance $\beta$-pinene, $\beta$-myrcene, 2 -carene, $\beta$-phellandrene, limonene, and terpinolene are constitutively emitted, while linalool and $\beta$-ocimene emission is induced after spider mite feeding (Kant et al. 2004). In this paper, we describe the first two monoterpene synthases from tomato, LeMTS1 and LeMTS2 and show that LeMTS1 is induced by $\mathrm{JA}$ in trichomes.

Identification of two tomato monoterpene synthases

In vitro assays with the recombinant LeMTS1 and LeMTS2 proteins show that LeMTS1 has both $(R)$-linalool synthase and $(E)$-nerolidol synthase activity, and that LeMTS2 is a $\beta$-phellandrene/ $\beta$-myrcene/sabinene synthase (Fig. 2a). LeMTS1 activity in planta seems restricted to linalool synthase activity since increased LeMTS1 expression by wounding, JA-treatment and ectopic overexpression led to increased linalool emission but did not affect nerolidol levels (Figs. 5, 9).

Generally speaking, monoterpene synthases are plastid targeted and use GPP, while sesquiterpene synthases use FPP in the cytosol. There are however some exceptions to this rule. For instance, a cytosolic strawberry nerolidol

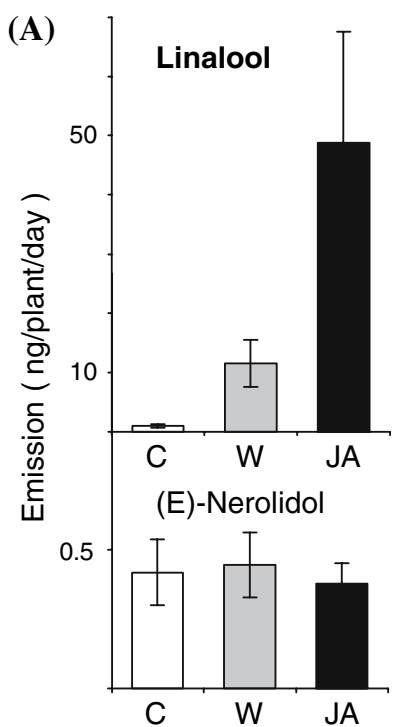

Fig. 9 Increased linalool emission. (A) Linalool and (E)-nerolidol emission by intact tomato plants that were wounded (W) or treated with $1 \mathrm{mM}$ jasmonic acid (JA) twice a day, for 2 days. The bar-graph shows the average $(n=3)$ emission over 2 days compared to the control and standard errors. Data (corrected for unequal variances) were analyzed by means of ANOVA followed by a Fishers-LSD post hoc-test. Linalool emission for both JA and wounding treatments was significantly increased compared to the control $(\mathrm{P}<0.05)$, whereas (E)-nerolidol emission was not. (B) Linalool emission by a transgenic

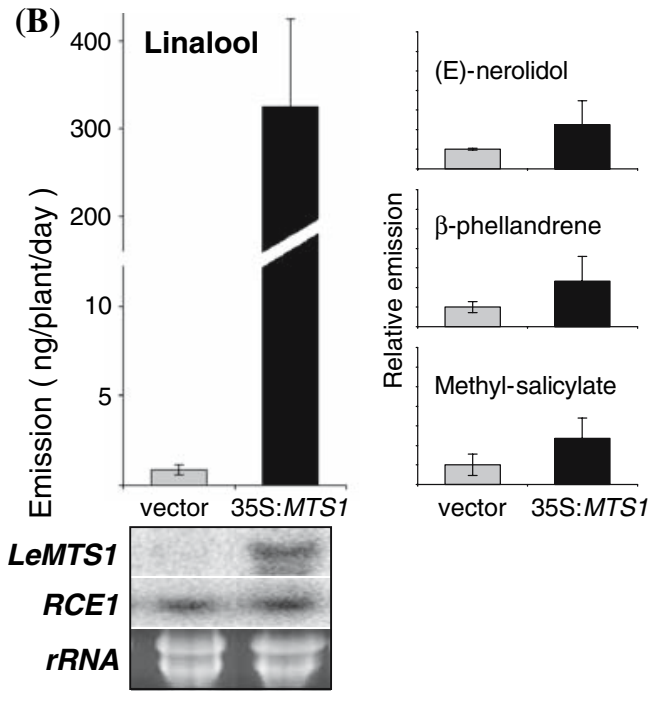

tomato line overexpressing LeMTS1. Headspaces were sampled from desiccators containing two plants each and compared to that of plants transformed with the empty vector. The graph expresses average values and standard deviations of four measurements. Emission of (E)-nerolidol, $\beta$-phellandrene, and methyl-salicylate did not significantly differ between plants. LeMTS1 overexpression in leaves was confirmed by RNA gel-blot analysis. The expression of RUB1 conjugating enzyme (RCE1) and ribosomal RNA levels (ethidium bromide-stained gel) are shown to indicate equal loading of the gel 
synthase (FaNES1) has both $(3 S)(E)$-nerolidol synthase and $S$-linalool synthase activity and is likely responsible for both linalool and nerolidol synthesis in planta (Aharoni et al. 2004). Vice versa, when FaNES1 was targeted to the plastid in Arabidopsis it also produced both linalool and nerolidol (Aharoni et al. 2003). The authors suggested that GPP and FPP substrate pools are not strictly separated between the cytosol and plastid, which has recently been supported by similar engineering experiments in tobacco (Wu et al. 2006). These observations might be explainable by for instance cytosolic as well as plastidial targeting of GPP synthase (GPS) in Arabidopsis and Litospermum erythrorizon (Bouvier et al. 2000; Sommer et al. 1995). In addition, FPP might be transported from the cytosol into plastids (Lichtenthaler 1999) and finally, the prenyltransferases GPS, FPS or GGPS might generate multiple products. However, since induced LeMTS1 expression does not correlate with increased nerolidol emission but only with increased linalool emission (Figs. 5, 9), we consider LeMTS1 to be a linalool synthase. Furthermore, we hypothesize that the plastidial FPP concentrations in tomato are negligible.

Despite their high sequence homology (Fig. 1), LeMTS1 and LeMTS2 have different biochemical activities. It is commonly found that different terpene synthases within one plant species often have higher sequence similarity to one another than to functionally related terpene synthases of other plant species. For example, $\beta$-pinene synthase from citrus (Citrus limon) is more homologous to the citrus $\gamma$-terpinene synthase than to $\beta$-pinene synthase from wormwood (Fig. 2). It is also known from work with other terpene synthases that product specificity can depend on only a few amino acids (Kollner et al. 2004; Rising et al. 2000; Yoshikuni et al. 2006) and thus, product specificity of terpene synthases is not predictable on basis of protein sequence or specific amino acid residues. By comparing terpene synthase structures, attempts have been made to ascribe substrate binding and substrate modifications to certain residues. Modeling of the active sites of a Salvia (Salvia officinalis) sabinene synthase, a mint (Mentha citrata) limonene synthase and a mint linalool synthase led to the following observation (Crowell et al. 2002): compared to the other two enzymes, the linalool synthase has a three amino acid deletion in the active site pocket (two amino acids after the conserved D591, see Fig. 1), resulting in a more open structure of the so called $\mathrm{J} / \mathrm{K}$ loop and providing an easier access of water during substrate ionization. Water access results in the premature release of the intermediate monoterpenol carbo-cation, before cyclization to a monoterpene olefin (non-hydrated) can occur. The tomato linalool synthase LeMTS1 also has a deletion in the active site pocket after the conserved D586 (Fig. 1). Although the deletion is eight instead of three amino acids, it indicates that LeMTS1 might utilize a similar structural mechanism to generate a monoterpene alcohol.

LeMTS1 expression correlates with induced linalool emission

The induction of LeMTS1 expression correlated with the increased emission of linalool by tomato plants. Wounding and JA application induced LeMTS1 (Fig. 5) as well as linalool emission (Fig. 9a). Induction of LeMTS1 upon spider mite-feeding (Fig. 5) coincided with linalool emission (Kant et al. 2004) in the tomato cultivar CM. Moreover, overexpression of LeMTS1 resulted in enhanced production of linalool (Fig. 9b) and no other volatile terpenes, providing evidence for in planta linalool synthase activity of LeMTS1. RNAi lines suppressing LeMTS1 expression in trichomes would provide additional evidence that LeMTS1 acts as a linalool synthase in planta.

It is generally known that successful overexpression of terpene synthases can be problematic (reviewed by Chappell 2004). Substrate limitation and product conversions can explain low-terpene production levels (Aharoni et al. 2003; Lucker et al. 2001; Ohara et al. 2003). In addition, ectopic terpene synthase overexpression might lead to product toxicity (Aharoni et al. 2006; Besumbes et al. 2004) and selection for plant lines with low transgene expression or low terpene accumulation (Diemer et al. 2001; Krasnyanski et al. 1999). We managed to regenerate only one LeMTS1 overexpressing plant line after four successive, independent transformations. The empty vector and unrelated constructs gave at least 20-fold higher transformation frequencies. Similarly, LeMTS2 overexpression was unsuccessful, seven transgenic plant lines showed only expression of truncated transcripts (data not shown).

LeMTS2 is expressed in roots, stems and petioles (Fig. 4a). In roots, only minute amounts of the main LeMTS2 product $\beta$-phellandrene were detected, hardly visible in Fig. 8 since levels are $\sim 300$-fold lower than in leaves. The role of monoterpenes in roots remains unclear, although they might play a role in the defense response of plants. The release of the monoterpene 1,8-cineole from Arabidopsis roots is induced upon bacterial pathogen infection (Steeghs et al. 2004), although transcriptional regulation of the corresponding 1,8-cineole synthase (Chen et al. 2004) has not been shown yet.

Although LeMTS2 is hardly expressed in tomato leaves (Fig. 4a), $\beta$-phellandrene and $\beta$-myrcene are constitutively emitted by tomato plants (Buttery et al. 1987; Kant et al. 2004). This suggests that the constitutive low expression of LeMTS2 might be sufficient to generate these monoterpenes. However, like the majority of volatile terpenes (data not shown), $\beta$-phellandrene is mostly located in trichomes 
(Fig. 8) where LeMTS2 is not expressed (Fig. 4b). This indicates that there are other $\beta$-phellandrene/ $\beta$-myrcene synthases in tomato that synthesize these terpenes.

\section{JA-induced LeMTS1 expression occurs in trichomes}

Although the presence of terpene synthases in trichomes has been well documented (Bertea et al. 2006; Iijima et al. 2004; Lange et al. 2000), the regulation of their expression in trichomes remains obscure. Here we show that JA treatment of intact plants leads to higher transcript levels of LeMTS1 mainly in trichomes (Fig. 7). In contrast, WIPI-II expression is induced by $\mathrm{JA}$ in the complementary tissues, indicating that there is a tissue-specific differential activation of JA-regulated genes. Basal expression of WIPI-II was very low in tomato trichomes, although constitutive expression of a WIPI-II in glandular trichomes was recently demonstrated in nightshade (Solanum americanum) (Liu et al. 2006). It is unknown whether trichome-expressed WIPI-II plays a role in the defense against herbivores. Induction of WIPI-II in non-glandular tissue (mesophyll/parenchyma) meets the expectation that it should be present in those cells that suffer from herbivory.

Previously, JA has been shown to increase trichome density on newly formed leaves of, for instance, Arabidopsis and tomato (Boughton et al. 2005; Traw and Bergelson 2003). Also, JA might induce trichome-based defenses directly. The production of acylsugars on the leaf surface (probably in trichomes) of Datura wrightii plants increased without affecting trichome density (Hare and Walling 2006). More clearly, nornicotin production on the Nicotiana repanda plant surface increased twofold within $6 \mathrm{~h}$ of JA treatment (Laue et al. 2000). Although it should be kept in mind that in the two above-mentioned studies, it was perhaps unjustly assumed that $\mathrm{CHCl}_{3}$ or $\mathrm{CH}_{2} \mathrm{Cl}_{2}$ extraction releases only trichome contents, it indicates that trichome-based secondary metabolite biosynthesis can be inducible. Results from our study show, for the first time, a specific transcriptional regulation of a gene involved in secondary metabolite biosynthesis in trichomes. Isolation of trichomes revealed that linalool synthase expression in tomato trichomes was induced more than twofold by JA after $24 \mathrm{~h}$.

In this paper, we report the identification of the first two monoterpene synthases from a plant of the solanaceae family. As it has recently been described that increased volatile terpene production in transgenic plants can benefit the indirect defense (Kappers et al. 2005; Schnee et al. 2006), it will be interesting to investigate the biological effect of LeMTS1 overexpression in tomato. Furthermore, the role of LeMTS2-derived terpenes in roots and stems remains to be investigated. Finally, the specific induction of LeMTS1 in trichomes by JA can provide an excellent opportunity for identification of novel, JA-related promoter elements, and transcription factors.

\section{Materials and methods}

\section{Isolation of LeMTS1 and LeMTS2 cDNAs}

Tomato plants, Lycopersicon esculentum cv. Moneymaker (3-4 weeks old) were infested with 150 spider mites (Tetranychus urticae) as described by Kant et al. (2004). Leaves were collected and pooled after 2-5 days of infestation. RNA was isolated using Trizol (Invitrogen, Carlsbad, CA, USA); cDNA was made using SuperscriptII RNAse $\mathrm{H}^{-}$(Invitrogen). A LeMTS fragment was amplified from this cDNA using the primer 5'-GATGACATTTATGATGTTTATGGC-3' in combination with an oligo dT(18) primer. The primer was designed based on putative tomato monoterpene synthases (www.tigr.org: TC168035, TC160168, BG131411, and cLED9K13) as such that it should not anneal to sesquiterpene synthase cDNAs. The 850 bp PCR product was cloned into pGEMT easy (Promega, Madison, WI, USA) and sequenced using the ABI PRISM BigDye terminator kit (Applied Biosystems, Foster city, CA, USA). cDNA was synthesized from leaves of 3-week-old Moneymaker plants and from hypocotyls and roots of 11-week-old Moneymaker plants with a ZAP-cDNA synthesis kit, cloned into the LambdaACT vector (Elledge et al. 1991) and packaged with a ZAP-cDNA Gigapack II gold cloning kit (Stratagene, La Jolla, CA, USA) 200,000 plaques of each library were screenend with the $850 \mathrm{bp}$ RT-PCR product as probe, radioactively labeled by the ALL-IN-ONE Random prime labeling method (Sigma, Saint Louis, MI, USA). Filters were hybridized at $55^{\circ} \mathrm{C}$ in BLOTTO hybridization buffer (Sambrook and Russell 2001) and washed three times for $10 \mathrm{~min}$ in $1 \times \mathrm{SSC}, 0.1 \% \mathrm{SDS}$ at $55^{\circ} \mathrm{C}$. DNA from positive plaques was converted to pAct 2 plasmids and their inserts were sequenced. LeMTS1 was obtained from the leaf cDNA library, LeMTS2 from the hypocotyl and root cDNA library. Sequences can be found in Genbank as AY840091 and AY840092, respectively. The presence of plastid targeting signals was predicted using PREDOTAR (http://genoplante-info.infobiogen.fr/predotar/predotar.html; Small et al. 2004) and TargetP (http:// www.cbs.dtu.dk/services/TargetP/; Emanuelsson et al. 2000).

Expression of recombinant proteins in E. coli, enzyme assays and product analysis

LeMTS1 and LeMTS2 were subcloned into the pET32-a expression vector (Novagen, San Diego, CA, USA) after 
removal of the plastid targeting signal sequences up to one amino acid upstream of the conserved arginine pair (Fig. 1) by generating 'truncated' LeMTS1 and LeMTS2 PCR products with $P f u$ DNA polymerase (Stratagene). Forward primers contained NcoI- and reverse primers XhoI-restriction sites. LeMTS1 primers $\left(5^{\prime}-3^{\prime}\right)$ : GATCCATGGACACAAGGCGTTCAGGGAATTAC and GTACTCGAGCAA AGTAATAAAATGAAGCCTACG, LeMTS2 primers: GATCCATGGGTATCCGACGTTCAGGAAATTAC and GTACTCGAGAATAAAAGGTAA TAATTCCTTGTC. pET32-LeMTS constructs were transformed into E. coli BL21(DE3) which were selected on Luria-Bertani (LB) plates containing $100 \mathrm{mg} / \mathrm{l}$ ampicillin. A single colony was grown overnight at $37^{\circ} \mathrm{C}$ on a plate, and transferred to $100 \mathrm{ml}$ of LB with ampicillin. Cultures were grown at $37^{\circ} \mathrm{C}$ for $30-60 \mathrm{~min}$ to $\mathrm{A}_{600}$ of $0.6-1.0$ before addition of $1 \mathrm{mM}$ isopropyl-1-thio$\beta$-D-galactopyranoside and grown at $20^{\circ} \mathrm{C}$ for an additional $8 \mathrm{~h}$. Cells were harvested by centrifugation and resuspended in $5 \mathrm{ml}$ monoterpene synthase assay buffer containing $50 \mathrm{mM}$ HEPES pH 7.5, $10 \%$ glycerol, $5 \mathrm{mM}$ DTT, $2 \mathrm{mM} \mathrm{MnCl}_{2}$, $10 \mathrm{mM} \mathrm{MgCl}_{2}$, proteinase inhibitor cocktail Complete (Roche, Basel, Switzerland), and $1 \mathrm{mM}$ ascorbic acid. Cells were disrupted by addition of $1 \mathrm{mg} / \mathrm{ml}$ lysozym (Sigma), incubation on ice for $30 \mathrm{~min}$ and sonication. After centrifugation $(10,000 \mathrm{~g})$ for $30 \mathrm{~min}$ at $4^{\circ} \mathrm{C}, 1 \mathrm{ml}$ of the soluble enzyme fraction was assayed directly, or after purification of the His-tagged recombinant fusion protein on Ni-agarose beads (Novagen) for monoterpene, sesquiterpene or diterpene synthase activity using $10 \mu \mathrm{M}$ of the substrates GPP, FPP or GGPP, respectively. The assay mix was incubated in a closed $20 \mathrm{ml}$ vial at $30^{\circ} \mathrm{C}$ for $1 \mathrm{~h}$ under gentle shaking $(150 \mathrm{rpm})$. Reaction products were sampled with a Solid Phase Micro Extraction fiber (SPME) for 10 min during which the vial was agitated and heated to $50^{\circ} \mathrm{C}$. The SPME fiber was desorbed $1 \mathrm{~min}$ in an Optic injector port (ATAS GL Int., Zoeterwoude, The Netherlands) which was kept at $250^{\circ} \mathrm{C}$. Compounds were separated on a DB-5 column $(10 \mathrm{~m} \times 180 \mu \mathrm{m}, 0.18 \mu \mathrm{m}$ film thickness; Hewlett Packard, Palo Alto CA, USA) in an 6,890 N gas chromatograph (Agilent, Amstelveen, The Netherlands) with a temperature program set to $40^{\circ} \mathrm{C}$ for $1.5 \mathrm{~min}$, ramp to $250^{\circ} \mathrm{C}$ at $30^{\circ} \mathrm{C} / \mathrm{min}$ and $250^{\circ} \mathrm{C}$ for an additional $2.5 \mathrm{~min}$. Helium was used as carrier gas, the column flow was set to $3 \mathrm{ml} / \mathrm{min}$ for $2 \mathrm{~min}$ and to $1.5 \mathrm{ml} / \mathrm{min}$ thereafter. Mass spectra were generated with the ion source set to $-70 \mathrm{~V}$ at $200^{\circ} \mathrm{C}$ and collected with a Time-of-Flight MS (Leco, Pegasus III, St. Joseph, MI, USA) at 1,671 V, with an acquisition rate of $20 \mathrm{scans} / \mathrm{s}$. Terpene products were identified using authentic standards and comparison of ion specra and relative retention times (Adams 2001). For separation of terpene enantiomers, a Cyclosil-B column $(30 \mathrm{~m} \times 247 \mathrm{~mm}$, $0.25 \mu \mathrm{m}$ film thickness; Agilent) was used. The temperature program was isothermal at $115^{\circ} \mathrm{C}$ for $15 \mathrm{~min}$, with a final ramp to $240^{\circ} \mathrm{C}$ at $120^{\circ} \mathrm{C} / \mathrm{min}$ and $240^{\circ} \mathrm{C}$ for $5 \mathrm{~min}$. Column flow was $0.7 \mathrm{ml} / \mathrm{min}$.

Plant treatments, plant headspace sampling, trichome isolation, and measurement of extracts

For determining tissue specific gene expression, a 13 weeks old, untreated tomato plant was dissected to obtain material of each of the described tissues. For separation of trichomes from petioles and stems, 4-week-old plants were used. Trichomes were collected on the bottom of a $50 \mathrm{ml}$ tube after vortexing several $\mathrm{N}_{2}(\mathrm{l})$-frozen petiole or stem segments, standing in upright position. The trichome fraction was used directly, whereas the remaining cleaned petiole or stem segments were thoroughly brushed to remove all remaining trichome material. Wounding-, spider mite-, and hormone-treatments (for both volatile sampling and gene expression analysis) were done using 3-4-week-old tomato plants. Wounding was inflicted by squeezing leaflets several times with a hemostat; a total of 150 spider mites were put on 3-4 leaflets per plant for 3 days; JA and salicylic acid were applied to plants by spraying $1 \mathrm{mM}$ solutions made with tap water containing $0.05 \%$ SilwetL-77. Wounding- and hormone-treatments were done (cumulative) at $0 \mathrm{~h}$ and at $18 \mathrm{~h}$ and leaves were sampled at $24 \mathrm{~h}$. Headspace sampling of plants was performed as described by Kant et al. (2004). Tenax sampling tubes were eluted with pentane : diethyl ether (4:1). The Eluted fractions were concentrated 20 times under a stream of $\mathrm{N}_{2}$ and $1 \mu \mathrm{l}$ was injected into the GC injector port. For root-, leaf-, trichome-, stem- or petiole-extracts, $0.5 \mathrm{~g}$ tissue was used. The amount of trichome material was adjusted to be equivalent to the trichomes present on $0.5 \mathrm{~g}$ of the original stem or petiole. Tissues were ground in $\mathrm{N}_{2}(\mathrm{l})$ and transferred to glass $20 \mathrm{ml}$ vials containing $2 \mathrm{ml}$ saturated $\mathrm{CaCl}_{2}(5 \mathrm{M})$ buffered in $100 \mathrm{mM}$ sodium acetate $(\mathrm{pH}$ 4.5) which were capped immediately and kept at $5^{\circ} \mathrm{C}$. Extracts were pre-incubated for $5 \mathrm{~min}$ at $60^{\circ} \mathrm{C}$ under agitation $(500 \mathrm{rpm})$ and sampled for $10 \mathrm{~min}$ at $60^{\circ} \mathrm{C}$ on a $100 \mu \mathrm{M}$ PDMS SPME fiber (Supelco, Zwijndrecht, The Netherlands). The SPME fiber was desorbed $1 \mathrm{~min}$ in the injector port of the GC/MS, which was kept at $250^{\circ} \mathrm{C}$. GC/ MS analysis was done as described earlier (Kant et al. 2004).

Gene expression analysis by RT-PCR and real-time QRT-PCR

For semi-quantitative RT-PCR, the tomato RUB1 conjugating enzyme (RCE1) was used as constitutively expressed control gene (www.tigr.org: TC153679). Initial PCR was performed with $R C E 1$ primers, product levels were com- 
pared and individual cDNA samples were diluted accordingly, to ensure equal template concentrations. PCRs with primers of genes of interest were subsequently performed for non-saturating number of amplification cycles. RCE1 primers were always included in each experiment. Used primers $\left(5^{\prime}-3^{\prime}\right)$ for RCE1: forward (F) GATTCTCTC TCATCAATCAATTCG; reverse (R) GCATCCAAACTTTACAGACTCTC, WIPI-II: F: GACAAGGTACTAGT AATCAATTATCC; R: CACATAACACACAACTTTGAT GCC, PRP6: F: TCAGTCCGACTAGGTTGTGG; R: TAG ATAAGTGCTTGATGTGCC, LeMTS1: F: GATGACAT TTATGATGTTTATGGC; R: GGCCATCTCGAGACTTG AGAGCGAATGCAACATTAG, LeMTS2: F: GATGA CATTTATGATGTTTATGGC; R: GGGTAATAATTC CTTGTCTTATTTC. Expression differences were validated by varying the amount of PCR cycles.

For real-time Q-RT-PCR, total RNA was isolated using Trizol (Invitrogen) and DNA was subsequently removed with DNAse (Ambion, Huntingdon, UK). cDNA was synthesized from $5 \mu \mathrm{g}$ RNA using SuperscriptII (Invitrogen) in $20 \mu \mathrm{l}$ reaction volume that was diluted to $50 \mu \mathrm{l}$ prior to using it for PCR. PCRs were performed in the ABI 7500 Real-Time PCR System (Applied Biosystems) using the Platinum SYBR Green qPCR SuperMix-UDG kit (Invitrogen). About $20 \mu \mathrm{l}$ PCR reactions contained $0.25 \mu \mathrm{M}$ of each primer, $0.1 \mu \mathrm{l}$ ROX reference dye, and $1 \mu \mathrm{l}$ template. The cycling program was set to $2 \min 50^{\circ} \mathrm{C}, 5 \min 95^{\circ} \mathrm{C}, 40$ cycles of $15 \mathrm{~s}$ at $95^{\circ} \mathrm{C}$ and $1 \mathrm{~min} 60^{\circ} \mathrm{C}$, and a melting curve analysis. Primer pairs were tested for specificity and for linearity with a standard cDNA dilution curve. Primers used: LeRCE1 QF: 5'-GATTCTCTCTCATCAATCAATTCG-3' QR: 5'-GAACGTAAATGTGCCACCCATA-3', LeWIPI2 (K03291) QF: 5'-GACAAGGTACTAGTAATCAATTATCC-3' QR: 5'-GGGCATATCCCGAACCCAAGA-3', LeMTS1 (AY8 40091) QF: 5'-TTTGGGGACATCTTCGGATGAA-3' QR: 5'-CTACTCGAGTTACTTGAGAGCGAATG CAAC-3'. Expression levels were normalized using RCE1 mRNA levels.

\section{Generation of transgenic tomato plants}

The complete LeMTSI cDNA, including the putative signal peptide, was cloned into the EcoRI-digested and Klenowblunted binary vector pGreen1K (Brandwagt et al. 2002), resulting in a CaMV35S:MTS1:nos cassette. The construct was transferred to Agrobacterium tumefaciens strain EHA105 carrying the pSoup helper plasmid (Hellens et al. 2000). Tomato plants cv. Moneymaker were transformed essentially as described by Vanroekel et al. (1993). Heterozygous and homozygous LeMTS1 overexpressing plants were used to measure linalool production by sampling the headspace of intact plants (four sets of two plants for both LeMTS1 overexpressors and control plants).
Acknowledgments We thank Kai Ament and Rinse Jaarsma for assistance with trichome isolation and Q-PCR, the Phytopathology department for providing the cDNA libraries, Frans van der Wielen for advices and technical assistance with the GC/TOF-MS and Harold Lemereis and Ludeck Tikovsky for their care of the tomato plants.

\section{References}

Adams RP (2001) Identification of essential oil components by gas chromatography/quadrupole mass spectroscopy. Allured Publishing Corporation, Carol Stream, IL

Aharoni A, Giri AP, Deuerlein S, Griepink F, de Kogel WJ, Verstappen FW, Verhoeven HA, Jongsma MA, Schwab W, Bouwmeester HJ (2003) Terpenoid metabolism in wild-type and transgenic Arabidopsis plants. Plant Cell 15:2866-2884

Aharoni A, Giri AP, Verstappen FW, Bertea CM, Sevenier R, Sun Z, Jongsma MA, Schwab W, Bouwmeester HJ (2004) Gain and loss of fruit flavor compounds produced by wild and cultivated strawberry species. Plant Cell 16:3110-3131

Aharoni A, Jongsma MA, Kim T, Ri M, Giri AP, Verstappen FW, Schwab W, Bouwmeester HJ (2006) Metabolic engineering of terpenoid biosynthesis in plants. Phytochem Rev 5:49-58

Ament K, Kant MR, Sabelis MW, Haring MA, Schuurink RC (2004) Jasmonic acid is a key regulator of spider mite-induced volatile terpenoid and methyl salicylate emission in tomato. Plant Physiol 135:2025-2037

Arimura G, Huber DP, Bohlmann J (2004a) Forest tent caterpillars (Malacosoma disstria) induce local and systemic diurnal emissions of terpenoid volatiles in hybrid poplar (Populus trichocarpa $\mathrm{x}$ deltoides): cDNA cloning, functional characterization, and patterns of gene expression of (-)-germacrene D synthase, PtdTPS1. Plant J 37:603-616

Arimura GI, Ozawa R, Kugimiya S, Takabayashi J, Bohlmann J (2004b) Herbivore-induced defense response in a model legume. Two-spotted spider mites induce emission of $(E)$ - $\{$ beta $\}$-ocimene and transcript accumulation of $(E)$-\{beta $\}$-ocimene synthase in lotus japonicus. Plant Physiol 135:1976-1983

Bertea CM, Voster A, Verstappen FW, Maffei M, Beekwilder J, Bouwmeester HJ (2006) Isoprenoid biosynthesis in Artemisia annua: cloning and heterologous expression of a germacrene A synthase from a glandular trichome cDNA library. Arch Biochem Biophys 448:3-12

Besumbes O, Sauret-Gueto S, Phillips MA, Imperial S, RodriguezConcepcion M, Boronat A (2004) Metabolic engineering of isoprenoid biosynthesis in Arabidopsis for the production of taxadiene, the first committed precursor of Taxol. Biotechnol Bioeng 88:168-175

Bohlmann J, Phillips M, Ramachandiran V, Katoh S, Croteau R (1999) cDNA cloning, characterization, and functional expression of four new monoterpene synthase members of the Tpsd gene family from grand fir (Abies grandis). Arch Biochem Biophys 368:232-243

Bohlmann J, Steele CL, Croteau R (1997) Monoterpene synthases from grand fir (Abies grandis). cDNA isolation, characterization, and functional expression of myrcene synthase (-)- (4S)-limonene synthase, and (-)-(1S,5S)-pinene synthase. J Biol Chem 272:21784-21792

Boughton AJ, Hoover K, Felton GW (2005) Methyl jasmonate application induces increased densities of glandular trichomes on tomato, Lycopersicon esculentum. J Chem Ecol 31:2211-2216

Bouvier F, Suire C, d'Harlingue A, Backhaus RA, Camara B (2000) Molecular cloning of geranyl diphosphate synthase and com- 
partmentation of monoterpene synthesis in plant cells. Plant $\mathrm{J}$ 24:241-252

Bouwmeester HJ, Verstappen FW, Posthumus MA, Dicke M (1999) Spider mite-induced (3S)-(E)-nerolidol synthase activity in cucumber and lima bean. The first dedicated step in acyclic C11-homoterpene biosynthesis. Plant Physiol 121:173-180

Brading PA, Hammond-Kosack KE, Parr A, Jones JD (2000) Salicylic acid is not required for Cf-2- and Cf-9-dependent resistance of tomato to Cladosporium fulvum. Plant J 23:305-318

Brandwagt BF, Kneppers TJA, Nijkamp HJJ, Hille J (2002) Overexpression of the tomato asc- 1 gene mediates high insensitivity to AAL toxins and fumonisin B-1 in tomato hairy roots and confers resistance to Alternaria alternata f. sp lycopersici in Nicotiana umbratica plants. Mol Plant-Microbe Interact 15:35-42

Buttery RG, Ling LC, Light DM (1987) Tomato leaf volatile aroma components. J Agric Food Chem 35:1039-1042

Cai Y, Jia JW, Crock J, Lin ZX, Chen XY, Croteau R (2002) A cDNA clone for beta-caryophyllene synthase from Artemisia annua. Phytochemistry 61:523-529

Cane DE, Xue Q, Fitzsimons BC (1996) Trichodiene synthase. Probing the role of the highly conserved aspartate-rich region by site-directed mutagenesis. Biochemistry 35:12369-12376

Chappell J (2004) Valencene synthase - a biochemical magician and harbinger of transgenic aromas. Trends Plant Sci 9:266-269

Chappell J, Nable R (1987) Induction of sesquiterpenoid biosynthesis in tobacco cell suspension cultures by fungal elicitor. Plant Physiol 85:469-473

Chen F, Ro DK, Petri J, Gershenzon J, Bohlmann J, Pichersky E, Tholl D (2004) Characterization of a root-specific Arabidopsis terpene synthase responsible for the formation of the volatile monoterpene 1,8-cineole. Plant Physiol 135:1956-1966

Crowell AL, Williams DC, Davis EM, Wildung MR, Croteau R (2002) Molecular cloning and characterization of a new linalool synthase. Arch Biochem Biophys 405:112-121

De Moraes CM, Lewis WJ, Pare PW, Alborn HT, Tumlinson JH (1998) Herbivore-infested plants selectively attract parasitoids. Nature 393:570-573

Degenhardt J, Gershenzon J (2000) Demonstration and characterization of $(E)$-nerolidol synthase from maize: a herbivore-inducible terpene synthase participating in (3E)-4,8-dimethyl-1,3,7-nonatriene biosynthesis. Planta 210:815-822

Dicke M (1994) Local and systemic production of volatile herbivoreinduced terpenoids - their role in plant-carnivore mutualism. J Plant Physiol 143:465-472

Diemer F, Caissard JC, Moja S, Chalchat JC, Jullien F (2001) Altered monoterpene composition in transgenic mint following the introduction of $4 \mathrm{~S}$-limonene synthase. Plant Physiol Biochem 39:603-614

Dudareva N, Cseke L, Blanc VM, Pichersky E (1996) Evolution of floral scent in Clarkia: novel patterns of S-linalool synthase gene expression in the C. breweri flower. Plant Cell 8:1137-1148

Dudareva N, Martin D, Kish CM, Kolosova N, Gorenstein N, Faldt J, Miller B, Bohlmann J (2003) (E)-beta-ocimene and myrcene synthase genes of floral scent biosynthesis in snapdragon: function and expression of three terpene synthase genes of a new terpene synthase subfamily. Plant Cell 15:1227-1241

Egea C, Alcazar MD, Candela ME (1996) Capsidiol: Its role in the resistance of capsicum annuum to phytophthora capsici. Physiol Plant 98:737-742

Elledge SJ, Mulligan JT, Ramer SW, Spottswood M, Davis RW (1991) Lambda-yes-a multifunctional cdna expression vector for the isolation of genes by complementation of yeast and escherichiacoli mutations. Proc Natl Acad Sci USA 88:1731-1735

Emanuelsson O, Nielsen H, Brunak S, von Heijne G (2000) Predicting subcellular localization of proteins based on their N-terminal amino acid sequence. J Mol Biol 300:1005-1016
Gershenzon J, McCaskill D, Rajaonarivony JI, Mihaliak C, Karp F, Croteau R (1992) Isolation of secretory cells from plant glandular trichomes and their use in biosynthetic studies of monoterpenes and other gland products. Anal Biochem 200:130138

Gomez SK, Cox MM, Bede JC, Inoue K, Alborn HT, Tumlinson JH, Korth KL (2005) Lepidopteran herbivory and oral factors induce transcripts encoding novel terpene synthases in Medicago truncatula. Arch Insect Biochem Physiol 58:114-127

Graham JS, Pearce G, Merryweather J, Titani K, Ericsson LH, Ryan CA (1985) Wound-induced proteinase inhibitors from tomato leaves. II. The cDNA-deduced primary structure of pre-inhibitor II. J Biol Chem 260:6561-6564

Hare JD, Walling LL (2006) Constitutive and jasmonate-inducible traits of Datura wrightii. J Chem Ecol 32:29-47

Hellens RP, Edwards EA, Leyland NR, Bean S, Mullineaux PM (2000) pGreen: a versatile and flexible binary Ti vector for Agrobacterium-mediated plant transformation. Plant Mol Biol 42:819-832

Howe GA, Lightner J, Browse J, Ryan CA (1996) An octadecanoid pathway mutant (JL5) of tomato is compromised in signaling for defense against insect attack. Plant Cell 8:2067-2077

Iijima Y, Gang DR, Fridman E, Lewinsohn E, Pichersky E (2004) Characterization of geraniol synthase from the peltate glands of sweet basil. Plant Physiol 134:370-379

Jia JW, Crock J, Lu S, Croteau R, Chen XY (1999) (3R)-Linalool synthase from Artemisia annua L.: cDNA isolation, characterization, and wound induction. Arch Biochem Biophys 372:143-149

Kant MR, Ament K, Sabelis MW, Haring MA, Schuurink RC (2004) Differential timing of spider mite-induced direct and indirect defenses in tomato plants. Plant Physiol 135:483-495

Kappers IF, Aharoni A, van Herpen TW, Luckerhoff LL, Dicke M, Bouwmeester HJ (2005) Genetic engineering of terpenoid metabolism attracts bodyguards to Arabidopsis. Science 309:2070-2072

Knudsen JT, Tollsten L, Bergstrom LG (1993) Floral scents-a checklist of volatile compounds isolated by headspace techniques. Phytochemistry 33:253-280

Kollner TG, Schnee C, Gershenzon J, Degenhardt J (2004) The variability of sesquiterpenes emitted from two Zea mays cultivars is controlled by allelic variation of two terpene synthase genes encoding stereoselective multiple product enzymes. Plant Cell 16:1115-1131

Krasnyanski S, May RA, Loskutov A, Ball TM, Sink KC (1999) Transformation of the limonene synthase gene into peppermint (Mentha piperita L.) and preliminary studies on the essential oil profiles of single transgenic plants. Theor Appl Genet 99:676682

Kutchan TM (2005) A role for intra- and intercellular translocation in natural product biosynthesis. Curr Opin Plant Biol 8:292-300

Lange BM, Wildung MR, Stauber EJ, Sanchez C, Pouchnik D, Croteau R (2000) Probing essential oil biosynthesis and secretion by functional evaluation of expressed sequence tags from mint glandular trichomes. Proc Natl Acad Sci USA 97:2934-2939

Langenheim JH (1994) Higher-plant terpenoids-a phytocentric overview of their ecological roles. J Chem Ecol 20:1223-1280

Laue G, Preston CA, Baldwin IT (2000) Fast track to the trichome: induction of $\mathrm{N}$-acyl nornicotines precedes nicotine induction in Nicotiana repanda. Planta 210:510-514

Lichtenthaler HK (1999) The 1-deoxy-D-xylulose-5-phosphate pathway of isoprenoid biosynthesis in plants. Annu Rev Plant Physiol Plant Mol Biol 50:47-65

Liu J, Xia KF, Zhu JC, Deng YG, Huang XL, Hu BL, Xu X, Xu ZF (2006) Nightshade proteinase inhibitor IIb gene is constitutively expressed in glandular trichomes. Plant Cell Physiol 47:12741284 
Lucker J, Bouwmeester HJ, Schwab W, Blaas J, van der Plas LH, Verhoeven HA (2001) Expression of Clarkia S-linalool synthase in transgenic petunia plants results in the accumulation of Slinalyl-beta-D-glucopyranoside. Plant J 27:315-324

Maluf WR, Campos GA, Cardoso MD (2001) Relationships between trichome types and spider mite (Tetranychus evansi) repellence in tomatoes with respect to foliar zingiberene contents. Euphytica 121:73-80

Martin D, Tholl D, Gershenzon J, Bohlmann J (2002) Methyl jasmonate induces traumatic resin ducts, terpenoid resin biosynthesis, and terpenoid accumulation in developing xylem of Norway spruce stems. Plant Physiol 129:1003-1018

McGarvey DJ, Croteau R (1995) Terpenoid metabolism. Plant Cell 7:1015-1026

Mercke P, Kappers IF, Verstappen FW, Vorst O, Dicke M, Bouwmeester HJ (2004) Combined transcript and metabolite analysis reveals genes involved in spider mite induced volatile formation in cucumber plants. Plant Physiol 135:2012-2024

Miller B, Madilao LL, Ralph S, Bohlmann J (2005) Insect-induced conifer defense. White pine weevil and methyl jasmonate induce traumatic resinosis, de novo formed volatile emissions, and accumulation of terpenoid synthase and putative octadecanoid pathway transcripts in Sitka spruce. Plant Physiol 137:369-382

Ohara K, Ujihara T, Endo T, Sato F, Yazaki K (2003) Limonene production in tobacco with Perilla limonene synthase cDNA. J Exp Bot 54:2635-2642

Pare PW, Tumlinson JH (1999) Plant volatiles as a defense against insect herbivores. Plant Physiol 121:325-332

Rising KA, Starks CM, Noel JP, Chappell J (2000) Demonstration of germacrene $\mathrm{A}$ as an intermediate in 5-epi-aristolochene synthase catalysis. J Am Chem Soc 122:1861-1866

Sacchettini JC, Poulter CD (1997) Creating isoprenoid diversity. Science 277:1788-1789

Sambrook J, Russell DW (2001) Molecular Cloning, a laboratory manual, 3rd edn. Cold Spring Harbor Laboratory Press, New York

Schnee C, Kollner TG, Gershenzon J, Degenhardt J (2002) The maize gene terpene synthase 1 encodes a sesquiterpene synthase catalyzing the formation of $(E)$-beta-farnesene $(E)$-nerolidol, and (E,E)-farnesol after herbivore damage. Plant Physiol 130:2049-2060

Schnee C, Kollner TG, Held M, Turlings TCJ, Gershenzon J, Degenhardt J (2006) The products of a single maize sesquiterpene synthase form a volatile defense signal that attracts natural enemies of maize herbivores. Proceeding of the National Academy of Sciences of the United States of America 103:1129-1134

Schwab W, Williams DC, Davis EM, Croteau R (2001) Mechanism of monoterpene cyclization: stereochemical aspects of the transformation of noncyclizable substrate analogs by recombinant (-)-limonene synthase (+)-bornyl diphosphate synthase, and (-)-pinene synthase. Arch Biochem Biophys 392:123-136

Shen B, Zheng Z, Dooner HK (2000) A maize sesquiterpene cyclase gene induced by insect herbivory and volicitin: characterization of wild-type and mutant alleles. Proc Natl Acad Sci USA 97:14807-14812

Small I, Peeters N, Legeai F, Lurin C (2004) Predotar: A tool for rapidly screening proteomes for $\mathrm{N}$-terminal targeting sequences. Proteomics 4:1581-1590

Snyder JC, Carter CD (1985) Trichomes on leaves of Lycopersicon hirsutum and L. esculentum and their hybrids. Euphytica 43:5364
Sommer A, Severin K, Camara B, Heide L (1995) Intracellular localization of geranyl pyrophosphate synthase from cell cultures of lithospermum erythrorhizon. Phytochemistry 38:623-627

Starks CM, Back KW, Chappell J, Noel JP (1997) Structural basis for cyclic terpene biosynthesis by tobacco 5-epi-aristolochene synthase. Science 277:1815-1820

Steeghs M, Bais HP, de Gouw J, Goldan P, Kuster W, Northway M, Fall R, Vivanco JM (2004) Proton-transfer-reaction mass spectrometry as a new tool for real time analysis of rootsecreted volatile organic compounds in Arabidopsis. Plant Physiol 135:47-58

Steele CL, Lewinsohn E, Croteau R (1995) Induced oleoresin biosynthesis in grand fir as a defense against bark beetles. Proc Natl Acad Sci USA 92:4164-4168

Takabayashi J, Dicke M (1996) Plant-carnivore mutualism through herbivore-induced carnivore attractants. Trends Plant Sci 1:109113

Takabayashi J, Shimoda T, Dicke M, Ashihara W, Takafuji A (2000) Induced response of tomato plants to injury by green and red strains of Tetranychus urticae. Exp Appl Acarol 24:377-383

Traw MB, Bergelson J (2003) Interactive effects of jasmonic acid, salicylic acid, and gibberellin on induction of trichomes in Arabidopsis. Plant Physiol 133:1367-1375

Turner G, Gershenzon J, Nielson EE, Froehlich JE, Croteau R (1999) Limonene synthase, the enzyme responsible for monoterpene biosynthesis in peppermint, is localized to leucoplasts of oil gland secretory cells. Plant Physiol 120:879-886

Turner GW, Croteau R (2004) Organization of monoterpene biosynthesis in Mentha. Immunocytochemical localizations of geranyl diphosphate synthase, limonene-6-hydroxylase, isopiperitenol dehydrogenase, and pulegone reductase. Plant Physiol 136:4215-4227

van Kan JA, Joosten MH, Wagemakers CA, van den Berg-Velthuis GC, de Wit PJ (1992) Differential accumulation of mRNAs encoding extracellular and intracellular PR proteins in tomato induced by virulent and avirulent races of Cladosporium fulvum. Plant Mol Biol 20:513-527

Van Poecke RM, Posthumus MA, Dicke M (2001) Herbivore-induced volatile production by Arabidopsis thaliana leads to attraction of the parasitoid Cotesia rubecula: chemical, behavioral, and geneexpression analysis. J Chem Ecol 27:1911-1928

Vanroekel JSC, Damm B, Melchers LS, Hoekema A (1993) Factors Influencing Transformation Frequency of Tomato (Lycopersicon-Esculentum). Plant Cell Rep 12:644-647

Whittington DA, Wise ML, Urbansky M, Coates RM, Croteau RB, Christianson DW (2002) Bornyl diphosphate synthase: structure and strategy for carbocation manipulation by a terpenoid cyclase. Proc Natl Acad Sci USA 99:15375-15380

Williams DC, McGarvey DJ, Katahira EJ, Croteau R (1998) Truncation of limonene synthase preprotein provides a fully active 'pseudomature' form of this monoterpene cyclase and reveals the function of the amino-terminal arginine pair. Biochemistry 37:12213-12220

Wu S, Schalk M, Clark A, Miles RB, Coates R, Chappell J (2006) Redirection of cytosolic or plastidic isoprenoid precursors elevates terpene production in plants. Nat Biotechnol 24:14411447

Yoshikuni Y, Ferrin TE, Keasling JD (2006) Designed divergent evolution of enzyme function. Nature 440:1078-1082 